\title{
Use of Nanotechnologies to Manage the Reliability of Fuel Equipment within Diesel Engines
}

Saidov M.A.

Department of Applied Mechanics and Engineering Graphics Grozny State Oil Technical University named after academician M.D. Millionshchikov

Grozny, Russia

saidoff@bk.ru

Dorokhov A.F.

Department of Shipbuilding and Energy Complexes of Marine Engineering

Astrakhan State Technical University

Astrakhan, Russia

dorokhovaf@rambler.ru

Makhmatkhadzhieva R.S.

Department of Applied Mechanics and Engineering Graphics Grozny State Oil Technical University named after academician M.D. Millionshchikov Grozny, Russia

makhmatkhadzhieva73@mail.ru

\section{Magomadova L.U.}

Department of Applied Mechanics and Engineering Graphics Grozny State Oil Technical University named after academician M.D. Millionshchikov

Grozny, Russia

laridi20@mail.ru

\begin{abstract}
The problem of increasing the efficiency of diesel engine fuel equipment is quite urgent due to the introduction of new environmental standards stipulating limited sulfur content in the fuel, which leads to the increase in the friction of precision pairs of fuel supply equipment and as a result causes increased wear of their contacting surfaces. The result of the solutions obtained in this work will allow increasing the resource of fuel equipment units and the use of fuels with ultra-low sulfur content, which is quite beneficial for the performance of the diesel engine as a whole and its negative impact on the environment.
\end{abstract}

Keywords-fuel equipment, low-sulfur diesel fuel, precision friction pairs, additives, nanoparticles, lubricity, plunger pair, injector spray nozzle, wear, erosion.

\section{INTRODUCTION}

Diesel engines play a significant role in the technical progress of the mankind. These have been the most efficient devices used to convert thermal energy into mechanical work since the time of Rudolf Diesel.

\author{
Shamsurkaev Kh.I. \\ Department of Life Safety \\ Grozny State Oil Technical University named after academician \\ M.D. Millionshchikov \\ Grozny, Russia \\ hhi67@mail.ru \\ Musaev A.A. \\ Department of Applied Mechanics and Engineering Graphics \\ Grozny State Oil Technical University named after academician \\ M.D. Millionshchikov \\ Grozny, Russia \\ brain_95@mail.ru
}

\section{Kozlova I.I.}

Department of Applied Mechanics and Engineering Graphics Grozny State Oil Technical University named after academician M.D. Millionshchikov Grozny, Russia

kozlova.i63@mail.ru

\section{Musaev S-M.S.}

Department of Applied Mechanics and Engineering Graphics Grozny State Oil Technical University named after academician

$$
\begin{gathered}
\text { M.D. Millionshchikov } \\
\text { Grozny, Russia } \\
\text { digital-95@mail.ru }
\end{gathered}
$$

At the same time, the efficiency of modern diesel engines still largely depends on the quality of the fuel equipment. According to some studies on the operation of diesel engines, the majority of engine malfunctions is mainly associated with functional disruptions of fuel equipment elements - these are primarily precision parts, such as plunger pairs of a high-pressure fuel pump and nozzles. Diameter variation of contacting surfaces of a pump pair and the cone seal of the injector spray nozzle increases the gaps due to their wear thus leading to the decrease in inject pressure, fuel leakage and affecting the operation of the diesel engine as such (Table 1) $[1,2]$.

In the recent past similar problems were leveled by the sufficient ability of diesel fuel to lubricate the friction surfaces of precision parts of fuel equipment. 
TABLE I. BREACH OF DIESEL ENGINE PERFORMANCE

\begin{tabular}{|c|c|}
\hline $\begin{array}{l}\text { Operating parameters } \\
\text { of the diesel engine }\end{array}$ & Reason for refusal \\
\hline Difficult start-up at idle & \multirow{7}{*}{$\begin{array}{c}\text { Leakage } \\
\text { plunger pair } \\
\text { (fuel leaks into space } \\
\text { behind the plunger) }\end{array}$} \\
\hline Difficult to start the heated engine & \\
\hline Unstable engine operation at idle & \\
\hline $\begin{array}{l}\text { Black smoke, reduced efficiency, reduced } \\
\text { power }\end{array}$ & \\
\hline $\begin{array}{l}\text { Blue light smoke, reduced power, possible } \\
\text { instability }\end{array}$ & \\
\hline $\begin{array}{l}\text { Overheating of the fuel equipment elements, } \\
\text { reducing the power of the diesel engine }\end{array}$ & \\
\hline Diesel engine overheating & \\
\hline
\end{tabular}

However, the latest requirements to environmental safety focus on the reduction of harmful emissions of exhaust gases. For this purpose, the new diesel fuel standards contain restrictions on sulfur content in fuels. This is explained by the fact that sulfur destroys and puts the catalysts of the purification system out of order thus causing pollution of the atmosphere. Oil refineries that supply diesel fuel face the problem of its lubricity since they have to comply with the requirements of European standard EN590 (Table 2).

TABLE II. QUALITY REQUIREMENTS FOR DIESEL FUELS ACCORDING TO EN 590

\begin{tabular}{|l|c|c|}
\hline \multirow{2}{*}{ Indicators } & \multicolumn{2}{|c|}{ EN590 } \\
\cline { 2 - 3 } & $\mathbf{1 9 9 6 - 1 9 9 9}$ & $\begin{array}{c}\text { Effective } \\
\text { since 2000 }\end{array}$ \\
\hline Mass fraction of sulfur, \% not more & 0.3 & 0.035 \\
\hline Cetane number, not less & 49 & 51 \\
\hline Density at $15^{\circ} \mathrm{C}, \mathrm{kg} / \mathrm{m}^{3}$ & $820-860$ & $840-845$ \\
\hline Kinematic viscosity at $40^{\circ} \mathrm{C}, \mathrm{mm}^{2} / \mathrm{s}$ & $2.0-4.5$ & $2.0-4.0$ \\
\hline $\begin{array}{l}\text { Fractional composition; } 95 \% \text { is distilled } \\
\text { to, }{ }^{\circ} \mathrm{C}\end{array}$ & 370 & 360 \\
\hline $\begin{array}{l}\text { Contains polyaromatic hydrocarbons, } \%, \\
\text { max }\end{array}$ & not normalized & 11 \\
\hline Lubricity no more than, $\mu \mathrm{m}$ & not normalized & 460 \\
\hline
\end{tabular}

With regard to the emphasized problem, recent attempts have been made to solve this technical issue. Design changes and selection of more wear-resistant and expensive materials are economically unjustified. The introduction of special anti-wear additives into the fuel is considered more rational. The studies confirm that with the decrease of sulfur content in the fuel below $0.05 \%$, it becomes necessary to introduce anti-wear additives. As a result, there is an increased number of patents in the world for anti-wear additives that reduce friction and consequently, wear of contact surfaces. $[3,9,10]$.

Additives based on naphthenic acids have a good reputation. For example, the additive "K".

However, they have a few disadvantages:

- penetration into the crankcase of the diesel engine and oil dilution;

- dangerous corrosion of the cylinder-piston group;

- deposits in the fuel equipment.

There are proposals to increase the lubricity of fuels by adding components such as vegetable oils, rape methyl ester, etc. The latter one is widely used in France, where tax incentives encourage the addition of up to $5 \%$ of this ester to fuel. However, it impairs the filterability of fuel and has low stability, which leads to the increase in carbonation in the injection system and the decomposition of lubricating oil. The local additives seem the most promising, i.e. such additives are not added to the total amount of fuel, but act directly on the friction unit. For example, an additive containing iron oxide nanoparticles and oleic acid molecules. The additive includes diesel fuel with micelles (Fig. 1) $[4,5]$.

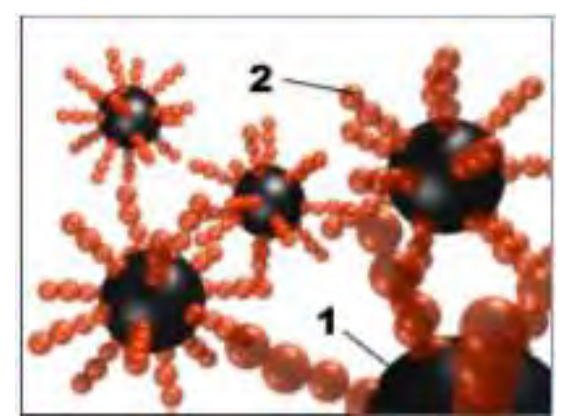

Fig. 1. Anti-wear additive for diesel fuel ( RU No. 2276681): 1 - iron oxide; 2 - molecules of oleic acid.

Micelles are composed of solid plastic grease molecules of iron oxide $\left(\mathrm{Fe}_{3} \mathrm{O}_{4}\right)$ and oleic acid molecules $\left(\mathrm{C}_{18} \mathrm{H}_{34} \mathrm{O}_{2}\right)$.

The additive has low shear resistance and increases the lubricity of diesel fuel.

The mechanism of action of the additive is reduced to the formation of a modified metal layer on friction surfaces ensuring uniform load distribution and reducing wear. The additive is fed to the friction unit with a dosing unit and is held on contacting surfaces by a magnetic field. At the same time, a metal-cladding layer with low shear resistance is formed on friction surfaces, thereby reducing friction and, as a result, wear. According to the Laboratory of Quality, Reliability and Performance Testing of the Central Scientific Institute of Fuel Equipment (CNITA, St. Petersburg), the device developed by the author for applying a magnetic additive in a nozzle atomizer allowed reducing the wear rate of the friction pair and increasing the coupling durability by $30 \%$. At the same time, there was a decrease in fuel leakage in the spray-injector interface. The proposed additive was used to improve the efficiency of diesel engine injectors.

This work proposes a study of devices for magnetic field guidance in a plunger pair. Thus, it is possible to increase the reliability of the most critical components and to reduce the fuel cost thus eliminating the need for full use of antiwear additives in fuel.

\section{METHODS AND MATERIALS}

So as to study the efficiency of anti-wear additives on a magnetic basis, accelerated cycle tests were carried out on a test bench to test the KI-921M fuel equipment of the Krasnoufimsky plant (Fig. 2). 


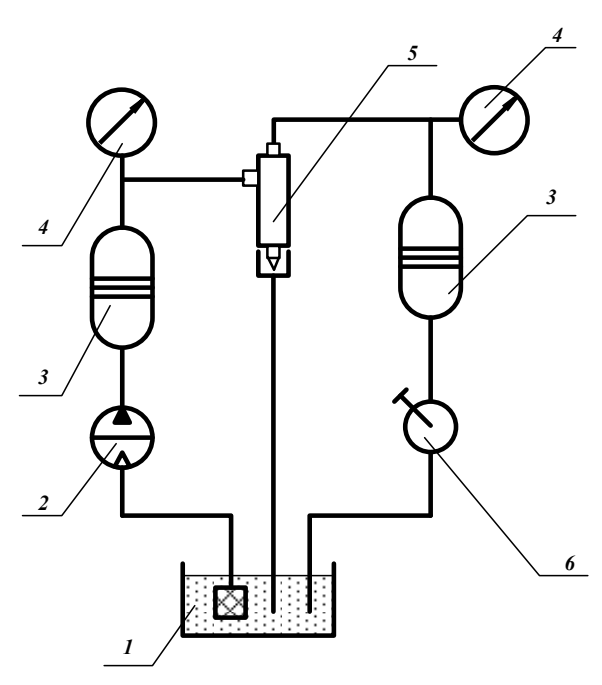

Fig. 2. Schematic diagram of KI-921M: 1 - fuel tank; 2 - high pressure pump; 3 - hydraulic accumulator; 4 - pressure measuring device; 5 nozzle; 6 - hand pump.

Calibrated standard nozzles of 16-C46-3B modification were used for pilot studies. These nozzles were equipped with a device for inducing a magnetic field in the cone seal of the nozzle (patent RU No. 2363859). In order to determine the wear by the gravimetric method the following devices were developed and patented: a device (patent RU No. 73920) to obtain the pattern of a nozzle spray seat; a device (patent RU№80513) to obtain the pattern of a needle sealing cone. When conducting developments at the stand KI-921M, diesel fuel with a sulfur content of $0.35 \%, 0.2 \%$ and $0.35 \%$ was used with the introduction of anti-wear additive. Under the action of a magnetic field the micelles of the additive were deposited on friction surfaces of the needle and the nozzle seat thereby forming a metal-cladding layer.

A device was developed to compensate for the wear of the contacting surfaces plunger - hub of the pumping section in order to be able to use an anti-wear additive on a magnetic basis in a plunger pair of a high-pressure diesel pump (Fig. 3).

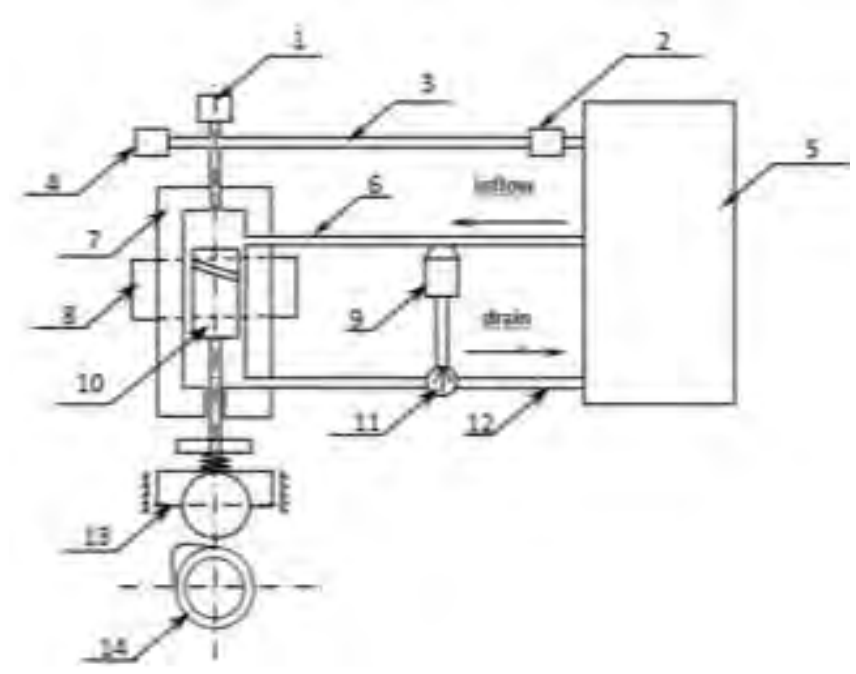

Fig. 3. Device of wear compensator of the plunger pair of the diesel engine fuel pump: 1 - pressure recorder; 2 - nozzle; 3 - high pressure pipeline; 4 - temperature recorder; 5 - tank for the working fluid; 6 - low pressure pipeline ; 7 - cylinder liner; 8 - clamp with permanent magnets; 9 - dispenser-receiver; 10 - plunger; 11 - three-way crane; 12 - fuel return line; 13 -device for giving rotational motion to the plunger; 14 - camshaft.

As a result of the induction of the magnetic field the nanoparticles of the additive are deposited on friction surfaces. Thereby the intensity of their wear decreases. In this case the additive layer compensates for the worn metal layer in the joint, which prevents the injected pressure from falling and reduces fuel leakage into the plunger space. [68].

The physicomechanical process of contacting their friction surfaces was analyzed to determine the wear of surfaces of the plunger pair. Figure 4 shows a structural model of a complex process of moving the plunger in the sleeve to represent the full connection of all parameters valid in the process. 


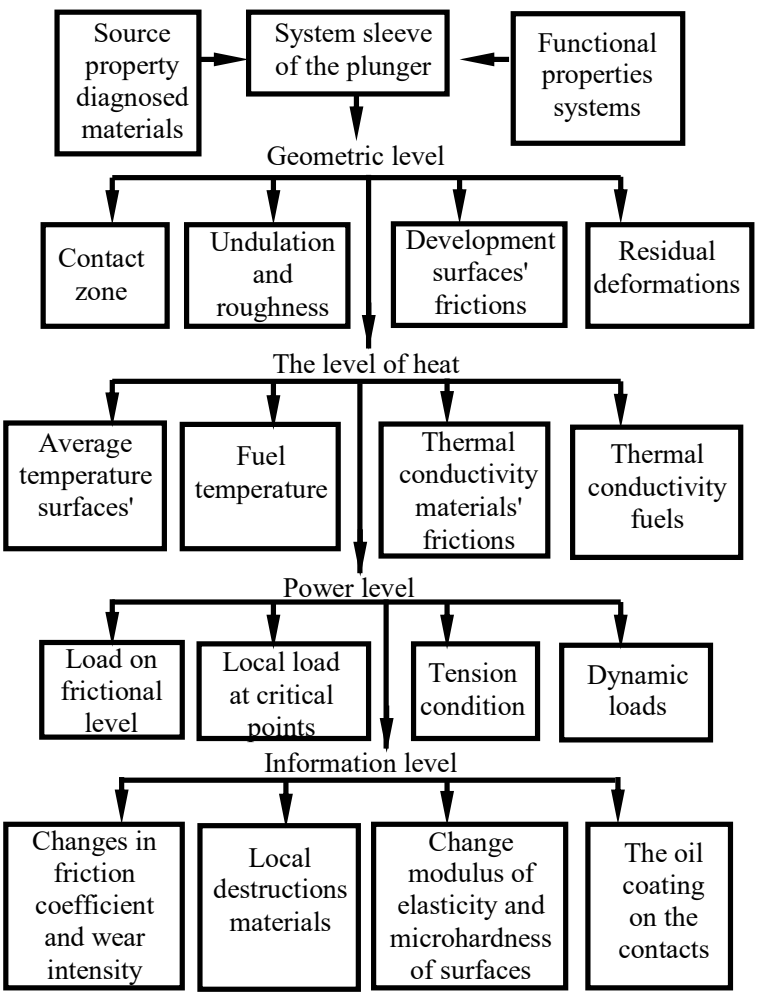

Fig. 4. Structural developing model of real complex multilevel tribological system (plunger-bushing)

When considering the physical nature of wear of a fuel pump plunger pair, the following factors were established. They influence the wear of this friction unit (Table 3). Each factor is expressed in the SI system using the dimension formula, which has four basic units: M - mass; L - length; $\mathrm{T}$ - time; $\theta$ - temperature. The dimension of each combined factor depends on the number of identical, simultaneously considered values. For instance, the temperature of surfaces of the plunger and the sleeve $\left[\theta^{2}\right]$, and not $[\theta]$, since the mean temperature of two bodies is taken into account

The independence of basic factors may be checked by making a determinant of the exponents of key units of measure with dimensions: $\mathrm{Z} ; \mathrm{n} ; \mathrm{R} ; \theta$. According to the Kramer's rule, if the determinant of the system is non-zero, then the solution is unique.

TABLE III. FACTORS AFFECTING THE WEAR OF THE FUEL PUMP PLUNGER PAIR.

\begin{tabular}{|c|c|c|c|}
\hline No. & Parameter & Dimension & Criteria \\
\hline 1 & Spring constant, $Z$ & $M T^{2}$ & \multirow{4}{*}{$\begin{array}{c}\text { Basic } \\
\text { parameter }\end{array}$} \\
\hline 2 & $\begin{array}{l}\text { The temperature of the plunger } \\
\text { and sleeve, } \theta\end{array}$ & $\theta^{2}$ & \\
\hline 3 & $\begin{array}{l}\text { The number of movements of } \\
\text { the plunger per unit of time, } n\end{array}$ & $T^{-1}$ & \\
\hline 4 & $\begin{array}{l}\text { The height of the surface } \\
\text { roughness, } R\end{array}$ & $L^{2}$ & \\
\hline 5 & Cyclic fuel supply, $q$ & $M$ & $\pi_{q}=\frac{q n^{2}}{Z}$ \\
\hline
\end{tabular}

\begin{tabular}{|c|c|c|c|}
\hline 6 & Surface reaction, $N$ & $M L^{-1} T^{-2}$ & $\pi_{p}=\frac{N \sqrt{R}}{Z}$ \\
\hline 7 & $\begin{array}{l}\text { Weight of movable parts of the } \\
\text { plunger pair, } m\end{array}$ & $M$ & $\pi_{m}=\frac{m n^{2}}{Z}$ \\
\hline 8 & $\begin{array}{l}\text { Endurance limit of the material } \\
\text { of the plunger and bushings, } \\
\sigma_{-1}\end{array}$ & $L^{-2} M^{2} T^{-4}$ & $\pi_{\sigma}=\frac{\sigma_{-1} R}{Z^{2}}$ \\
\hline 9 & Wear time, $T$ & $T$ & $\pi_{t}=T n$ \\
\hline 10 & Fuel temperature, $\theta_{T}$ & $\theta$ & $\pi_{\theta^{\prime}}=\frac{\theta_{T}}{\sqrt{\theta}}$ \\
\hline 11 & $\begin{array}{l}\text { Density of the material of the } \\
\text { plunger and sleeve, } \rho\end{array}$ & $M^{2} L^{-6}$ & $\pi_{\rho}=\frac{\rho n^{4} R^{3}}{Z^{2}}$ \\
\hline 12 & $\begin{array}{l}\text { Density of the material of the } \\
\text { plunger and sleeve, } H\end{array}$ & $L^{-2} M^{2} T^{-4}$ & $\pi_{H}=\frac{H R}{Z^{2}}$ \\
\hline 13 & Wear scar diameter, $D$ & $L$ & $\pi_{D}=\frac{D}{\sqrt{R}}$ \\
\hline 14 & $\begin{array}{l}\text { Thermal conductivity surfaces } \\
\text { plunger's and bushings, } \lambda\end{array}$ & $L^{2} M^{2} T^{-6}$ & $\pi_{\lambda}=\frac{\lambda \theta}{Z^{2}}$ \\
\hline 15 & $\begin{array}{l}\text { Coefficient of thermal } \\
\text { conductivity of fuel, } \lambda_{T}\end{array}$ & $L M T^{-3} \theta^{-1}$ & $\pi_{\lambda_{T}}=\frac{\lambda_{T} \sqrt{\theta}}{Z n \sqrt{R}}$ \\
\hline 16 & Elastic modulus, $E$ & $M^{2} L^{-2} T^{-2}$ & $\pi_{E}=\frac{E R}{Z^{2}}$ \\
\hline
\end{tabular}

\section{RESULTS}

With reference to the second similarity theorem the functional dependence of conjugation wear

can be expressed as follows:

$$
I_{h}=f\left(\frac{q n^{2}}{Z} ; \frac{N \sqrt{R}}{Z} ; \frac{m n^{2}}{Z} ; \frac{\sigma_{-1} R}{Z^{2}} ; T n ; \frac{\theta^{\prime}}{\sqrt{\theta}} ; \frac{\rho n^{4} R^{3}}{Z^{2}} ; \frac{H R}{Z^{2}} ; \frac{D}{\sqrt{R}} ; \frac{\lambda \theta}{Z^{2} n^{2} R} ; \frac{\lambda_{T} \sqrt{\theta}}{Z n \sqrt{R}} ; \frac{E R}{Z^{2}}\right)
$$

The analysis of the obtained criteria and their grouping in accordance with physical value of the phenomena being characterized allows presenting the similarity criteria in the form of generalized complexes:

$A_{d}=\frac{\rho n^{6} m \sqrt{R}}{E N}-$ complex characterizing the dynamics of the stress state of a contact;

$A_{u}=\frac{\sigma_{-1} T n}{H}-$ complex characterizing the fatigue strength of rubbing surfaces;

$A_{S}=\frac{\theta_{T} D q n \lambda}{Z^{2} R \lambda_{T}}-$ complex determining the relative thickness of the lubricant layer in a contact.

In the case of mechanical destruction of surfaces, the wear rate $I_{h}$ shall be found in the form of dependencies describing the process by the following physically informative (dimensionless) generalized factors:

$$
I_{h}=k A_{d}^{x} A_{u}^{y} A_{s}^{z},
$$

where $k$-matching factor.

The results of the experimental data allowed us obtaining coefficients in the criterial equation describing the plunger pair wear in dimensionless physically informative complexes: 
$I_{h}=1,618 \cdot A_{d}^{2,1} \cdot A_{u}^{1,4} \cdot A_{s}^{0,9}$ - fuel with sulfur content of $0.035 \%$;

$I_{h}=1,247 \cdot A_{d}^{1,6} \cdot A_{u}^{0,6} \cdot A_{S}^{0,2}-$ fuel with sulfur content of $0.2 \%$

$I_{h}=1,365 \cdot A_{d}^{1,8} \cdot A_{u}^{1,6} \cdot A_{s}^{1,2}$ - fuel with sulfur content of $0.035 \%$ with magnetic anti-wear additive.

By approximating the initial data using the least squares method, we get the curves describing the process under study (Fig. 5).

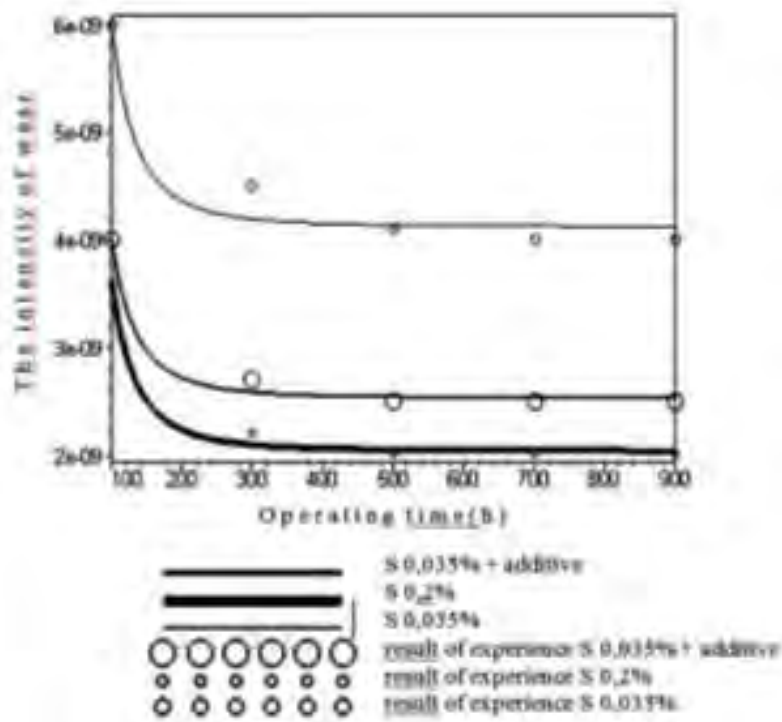

Fig. 5. Intensity of wear of plunger pairs

\section{CONCLUSIONS}

1. The presence of a plunger-bushing friction force in the coupling and multiple repetition of the process of their interaction, taking into account the boundary layer formed on the surfaces under conditions of continuous lubrication, makes it possible to use the model of fatigue mechanism of friction fracture of surfaces to calculate its wear rate.

2. It is more expedient to judge the qualitative connection of the parameters defining this process using the theory of dimension analysis due to the lack of a mathematical description of the influence of all factors on the wear of a plunger pair.

3. Having experimentally obtained the coefficients in the criterial dependences describing the wear rate of the plunger pair, we get the opportunity to determine the amount of wear at any time in the range of the intervals of the experiment.

\section{Acknowledgments}

The study is carried out within the framework of the agreement on mutual scientific and technical cooperation between Astrakhan State Technical University and the Central Research and Design Institute of Fuel Equipment for Automotive Tractor and Stationary Engines (CNITA, St. Petersburg), as well as under the agreement on mutual scientific and technical cooperation between Astrakhan State Technical University and Grozny State Oil Technical University named after academician M.D. Millionshchikov.

\section{References}

[1] Sung-Ho Hong, "A New Clearance Design Method for Reciprocating Fuel Pumps of Medium-Speed Diesel Engines," J. Tribology Transactions, Vol. 61, pp. 773-783, 2018.

[2] A. Bahari, R. Lewis \& T. Slatter, "Friction and Wear Phenomena of Vegetable Oil-Based Lubricants with Additives at Severe Sliding Wear Conditions," J. Tribology Transactions, Vol. 61, 2018, pp. 207219

[3] M.A. Salete, A.C. Mendes, V.S. Mello, "Effect of Soybean Biodiesel Addition on Tribological Performance of Ultra-Low Sulfur Diesel," J. Tribol, Vol. 141(2), Oct 16, 2018, pp. 8 .

[4] A.P. Perekrestov, A.A. Sychev, Antiwear additive, Patent RF No. 2276681, 2006, Bul. No. 14.

[5] A.B. Kisabo, "Comparative Analysis Between Cam and Cam-less Valve Actuating for Automotive System," J. Engineering and Applied Sciences, Vol. 2(5), pp. 89-98, 2017.

[6] M.A. Saidov, A.P. Perekrestov, "Influence of nanodispersed modifications of magnetite powders on spray nozzle efficiency of diesel engine injector," IOP Conf. Series: Earth and Environmental Science, Vol. 87, 2017, 082042

[7] M.A. Saidov, A.P. Perekrestov, S.M. Nogamirzaev, "Study of the wear of the plunger pair of the diesel engine fuel pump," J. Bulletin of Astrakhan State Technical University, Vol. 3, 2018, pp. 70-77.

[8] B.P. Bashurov, V.S. Chebanov, "Evaluation of the functional reliability of the elements of the fuel system of marine diesel engines in service," J. Dvigatelestroyeniye, Vol. 1, 2010, pp.34-36.

[9] P. Samanta, J. Dahiya, "Interface science and engineering for less friction and wear," J. Advances in Mechanical Engineering, 2017, Vol. 9(12).

[10] N. Brahma, S. Shailendra, "Combustion Characteristics of Diesel Combustion System Using Blended Diesel: An Experimental Study," American Journal of Mechanics and Applications, Vol. 5(4), pp. 3440,2017 